\title{
Amino acid substitutions of His296 alter the catalytic properties of Zymomonas mobilis 10232 levansucrase
}

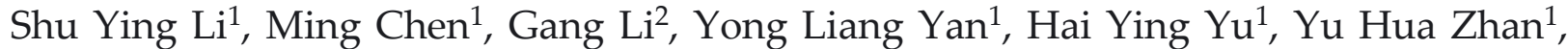 \\ Zi Xin Peng ${ }^{1}$, Jin Wang ${ }^{3 凶}$ and Min Lin ${ }^{1 凶}$ \\ ${ }^{1}$ Biotechnology Research Institute, Chinese Academy of Agricultural Sciences, Beijing, P.R. China; ${ }^{2}$ Sichuan \\ Habio Bioengineering Co. Ltd., Chengdu, Sichuan, P.R. China; ${ }^{3}$ Plant Genomics Research center, Mianyang \\ Normal College, Mianyang, Sichuan, P.R. China
}

Received: 23 October, 2007; revised: 29 January, 2008; accepted: 12 February, 2008 available on-line: 07 March, 2008

\begin{abstract}
His296 of Zymomonas mobilis levansucrase (EC 2.4.1.10) is crucial for the catalysis of the transfructosylation reaction. The three-dimensional structures of levansucrases revealed the His 296 is involved in the substrate recognition and binding. In this study, nine mutants were created by site-directed mutagenesis, in which His296 was substituted with amino acids of different polarity, charge and length. The substitutions of His296 with Arg or Trp retained partial hydrolysis and transfructosylation activities. The positively charged Lys substitution resulted in a 2.5-fold increase of sucrose hydrolysis. Substitutions with short (Cys or Ser), negatively charged (Glu) or polar (Tyr) amino acids virtually abolished both the activities. Analysis of transfructosylation products indicated that the mutants synthesized different oligosaccharides, suggesting that amino acid substitutions of His296 strongly affected both the enzyme activity and transfructosylation products.
\end{abstract}

Keywords: Zymomonas mobilis, levansucrase, His296, hydrolysis activity, transfructosylation activity, levan

\section{INTRODUCTION}

Levan, a $\beta$-(2 $\rightarrow 6)$-linked fructose polymer, has potential importance in food, pharmaceutical, medicine, cosmetics and textile industry (Swings \& De Ley, 1977; Kazap et al., 1980; Yun, 1996; Yamamoto et al., 1999). Bacterial levansucrase, an extracellular enzyme, is found in many Gram-positive and Gram-negative bacteria. Levansucrase possesses sucrose-hydrolyzing and transfructosylation activities which can transfer fructose units from sucrose to other sucrose molecules, forming high molecular mass levan, a reaction that occurs far more efficiently at lower temperatures and lower $\mathrm{pHs}$ (Yanase et al., 1992).
Levansucrases are categorized into GH (glycoside hydrolase) family 68 based on the phylogenetic analysis of the amino-acid sequences of glycosidases (Henrissat, 1991). Multiple alignments of available bacterial levansucrases reveal that they have five highly conserved regions (Yanase et al., 2002). The high-resolution crystal structures of Bacillus subtilis SacB (levansucrase) and Gluconacetobacter diazotrophicus LsdA (levansucrase) display a five-bladed $\beta$-propeller architecture. Levansucrases have a deep, negatively charged central pocket. The fructosyl unit of substrate sucrose is located at the bottom of the pocket and the glucosyl moiety on top. The molecular surface shows that the side chain of Arg331 (B. subtilis SacB) or His419 (G. diazotrophicus LsdA)

Corresponding author: M. Lin, Biotechnology Research Institute, Chinese Academy of Agricultural Sciences, Beijing 100081, P. R. of China; tel.: (86 10) 6213 9578; fax: (86 10) 6213 6981; e-mail: linmin57@vip.163.com; J. Wang, Plant Genomics Research center, Mianyang Normal College, Mianyang, Sichuan, 621000, P. R. of China; e-mail: wjdsz@vip.sina.com Abbreviations: HPAEC, high-performance anion-exchange chromatography; LB medium, Luria-Bertani medium; SacB/ LsdA, levansucrase; sacB, levansucrase gene. 
is located immediately adjacent to the central pocket. Arg331 or His419 interacts with the 2-OH and 3$\mathrm{OH}$ of the glucosyl residue in the active site (Meng \& Futterer, 2003; Martinez-Fleites et al., 2005).

The transfructosylation and hydrolysis activities of levansucrase can be separated. In Z. mobilis levansucrase the substitution of Ser for Cys residues 121, 151 and 244 abolished the levan-forming activity and halved the sucrose hydrolysis activity (Senthilkumar et al., 2003). Both Arg331 (B. subtilis SacB) and His296 (Z. mobilis SacB) mutations attenuated transfructosylation, but the hydrolyzing activity of the enzyme was unaffected. These substitutions reduced the efficiency of transfructosylation activities of the enzyme via decreasing the rate of fructosylenzyme intermediate formation, suggesting that the steric requirements of the active groups are much more important for polymerization than for hydrolysis (Chambert \& Petit-Glatron, 1991; Yanase et al., 2002; Martinez-Fleites et al., 2005). The Arg guanidine group and the His imidazole group are both positively charged and can form an electronic delocalizing plane (Chambert \& Petit-Glatron, 1991, Martinez-Fleites et al., 2005).

Z. mobilis levansucrase His296, located in homologous region IV, is equivalent to $B$. subtilis SacB Arg331 and G. diazotrophicus LsdA His419. In order to investigate the role of His296 in Z. mobilis levansucrase, we constructed nine mutants in which His296 was substituted with the following residues

Table 1. Oligonucleotides used for site-directed mutagenesis.

The nucleotide substitutions are indicated as lowercase.

\begin{tabular}{ll}
\hline Mutation & Mutagenesis primer (5' to 3') \\
\hline H296R & R2: 5'-AATGgcgACTGATCGTAAAGAGATAGG-3' \\
& R3: 5'-AGTcgcCATTCGACTTATGCCG-3' \\
H296W & W2: 5'-AATGccaACTGATCGTAAAGAGATAGG-3' \\
& W3: 5'-AGTtggCATTCGACTTATGCCG-3' \\
H296K & K2: 5'-AATGttACTGATCGTAAAGAGATAGG-3' \\
& K3: 5'-AGTaaCATTCGACTTATGCCG-3' \\
H296L & L2: 5'-AATGcaaACTGATCGTAAAGAGATAGG-3' \\
& L3: 5'-AGTttgCATTCGACTTATGCCG-3' \\
H296Q & Q2: 5'-AATGctgACTGATCGTAAAGAGATAGG-3' \\
& Q3: 5'-AGTcagCATTCGACTTATGCCG-3' \\
H296S & S2: 5'-AATGggaACTGATCGTAAAGAGATAGG-3' \\
& S3: 5'-AGTtcCATTCGACTTATGCCG-3' \\
H296C & C2: 5'-AATGacaACTGATCGTAAAGAGATAGG-3' \\
& C3: 5'-AGTtgtCATTCGACTTATGCCG-3' \\
H296E & E2: 5'-AATGttcACTGATCGTAAAGAGATAGG-3' \\
& E3: 5'-AGTgaaCATTCGACTTATGCCG-3' \\
& Y2: 5'-AATGataACTGATCGTAAAGAGATAGG-3' \\
\hline
\end{tabular}

that have different polar as well as electrostatic properties: Arg and Trp have steric structures (electronic delocalizing planes); Lys is positively charged but not steric; the side chains of Leu and Gln are neutral; Glu has a negative charge and Tyr is polar; Cys and Ser have short side chains. The purified enzymes were characterized kinetically and their transfructosylation products were determined.

\section{MATERIALS AND METHODS}

Bacterial strains, plasmids and growth conditions. Escherichia coli JM109 [recA, supE, endA, hsdR, gyr A, relA, thi, $\triangle$ (lac -proAB), Ftra, $\triangle$ proAB, lacIq, lacZ $\triangle M 15]$ was used as a host for gene cloning. All plasmids were derivatives of pEB1 (constructed by our lab, sacB ligated into pET28a), containing the Z. mobilis 10232 gene encoding levansucrase $(s a c B)$. Z. mobilis 10232 was bought from the China Center of Industrial Culture Collection (Beijing, China). E. coli JM109 cells harboring derivative plasmids (ligated into pMD18-T, Takara Shuzou, Otsu) were grown with shaking at $37^{\circ} \mathrm{C}$ in Luria-Bertani media (LB) supplemented with $50 \mu \mathrm{g} / \mathrm{ml}$ ampicillin. E. coli BL21 (DE3) [hsdSgal ( $\lambda c T_{s} 857$ indl Sam7nin5 laclVVT7gene1)] was used as the host to express site-directed mutants of Z. mobilis levansucrase.

Site-directed mutagenesis of the levansucrase gene. Site-directed mutagenesis was carried out using the 'megaprimer' method (Sarkar \& Sommer, 1990) with plasmid pEB1 as the template. The oligonucleotides used for mutagenesis (Table 1) were synthesized by Shanghai Sangon Co., Ltd. The plasmids containing the mutant genes (ligated into pMD18-T) were screened on LB agar with $50 \mu \mathrm{g} / \mathrm{ml}$ ampicillin.

The mutant genes were verified by sequencing and their BamHI and SalI fragments were subcloned into the BamHI and SalI sites of pET28a. The resulting plasmid was used to transform E. coli BL21 (DE3). Two flanking primers, SacBF (BamHI): 5'-GGATC CGGAA TGTTG AACAA AGCAG-3' and SacBR (SalI): 5'-GTCGA CGGAA TAGGA AGGGT GTC-3', were used in all reactions. The resultant mutant enzymes, in which His296 was substituted with Arg, Trp, Lys, Leu, Gln, Glu, Tyr, Cys or Ser, were designated as H296R, H296W, H296K, H296L, H296Q，H296E, H296Y, H296C and H296S, respectively.

Levansucrase purification. E. coli BL21 carrying a recombinant plasmid was cultured at $15^{\circ} \mathrm{C}$ in $200 \mathrm{ml}$ of $\mathrm{LB}$ 
medium containing $0.1 \mathrm{mM}$ isopropyl- $\beta$-D-1-thiogalactopyranoside (IPTG) and $50 \mu \mathrm{g} / \mathrm{ml}$ kanamycin. After $16 \mathrm{~h}$ the cultures were centrifuged at $5000 \times g$ for $5 \mathrm{~min}$, and the harvested cells were suspended in $10 \mathrm{ml}$ of NTA-0 buffer $(20 \mathrm{mM}$ Tris/ $\mathrm{HCl} \mathrm{pH} 7.9$, $0.25 \mathrm{M} \mathrm{NaCl}$, and $5 \%$ glycerol), and then disrupted by sonication. The supernatants of the recombinant enzymes (containing His-tag sequence at the N-terminus) were applied to a Ni-NTA columns (Qiagen, CA, USA) equilibrated with the same buffer, after which the bound enzyme was eluted with a linear imidazole gradient $(0$ to $0.1 \mathrm{M})$. Fractions exhibiting enzyme activity were pooled, dialyzed against 50 $\mathrm{mM}$ sodium acetate ( $\mathrm{pH} 5)$, and vacuum-concentrated (Christ alpha 1-2 LD plus, Germany); the purity was evaluated by SDS/PAGE. Protein was quantitated by the Bradford method (Bradford, 1976), with bovine serum albumin serving as the standard.

Enzyme activities assays. Sucrose hydrolysis activity was assayed in a standard reaction containing $1 \mathrm{ml} \mathrm{10 \%}$ sucrose and $1 \mathrm{ml}$ enzyme (0.01-0.05 $\mathrm{mg} / \mathrm{ml}$ ) incubated at $30^{\circ} \mathrm{C}$. The amount of glucose liberated was estimated by the method of Somogyi (1952; Ananthalakshmy \& Gunasekaran, 1999). One unit of sucrose-hydrolyzing activity was defined as the amount of enzyme that produced $1 \mu \mathrm{mol}$ of glucose per min under the experimental conditions.

The transfructosylation activity of levansucrase was assayed in a standard reaction containing $1 \mathrm{ml} \mathrm{10 \%}$ sucrose and $1 \mathrm{ml}$ enzyme (0.01-0.05 $\mathrm{mg} / \mathrm{ml}$ ) incubated at $15^{\circ} \mathrm{C}$. Turbidity was measured at $540 \mathrm{~nm}$, and the amount of levan generated was calculated from an established standard curve of absorbance against the concentration of purified $\mathrm{Z}$. mobilis levan (Sigma). One unit of transfructosylation activity was defined as the amount of the enzyme required to form $1 \mu \mathrm{g}$ of levan in $1 \mathrm{~min}$ under the experimental conditions (Ananthalakshmy \& Gunasekaran, 1999).

The kinetic parameters of sucrose hydrolysis were assayed in $50 \mathrm{mM}$ sodium acetate $(\mathrm{pH} 5.0)$ at $30^{\circ} \mathrm{C}$. The initial velocities of the liberation of glucose from sucrose were analyzed and intersecting curves were obtained that generated linear doublereciprocal plots. Apparent kinetic parameters were

Table 2. The kinetic parameters for sucrose hydrolysis of wild-type levansucrase and His296 variants

\begin{tabular}{lccc}
\hline \multirow{2}{*}{ Enzyme } & \multicolumn{3}{c}{ Kinetic parameters for sucrose hydrolysis } \\
\cline { 2 - 4 } & $k_{\text {cat }}\left(\mathrm{min}^{-1}\right)$ & $K_{\mathrm{M}}(\mathrm{mM})$ & $K_{\text {cat } /} k_{\mathrm{M}}\left(\mathrm{M}^{-1} \mathrm{~min}^{-1}\right)$ \\
\hline Wild type & $1.75 \times 10^{3}$ & 83.92 & $20.85 \times 10^{3}$ \\
H296R & $1.64 \times 10^{3}$ & 1825.71 & $0.90 \times 10^{3}$ \\
H296W & $1.06 \times 10^{3}$ & 727.75 & $1.46 \times 10^{3}$ \\
H296K & $4.45 \times 10^{3}$ & 6250.36 & $0.71 \times 10^{3}$ \\
H296L & $2.30 \times 10^{3}$ & 4508.73 & $0.51 \times 10^{3}$ \\
H296Q & $1.17 \times 10^{3}$ & 4250.41 & $0.27 \times 10^{3}$ \\
\hline
\end{tabular}

calculated for the sucrose hydrolyzing activity. The sucrose concentration ranged from 24 to $1000 \mathrm{mM}$, and the enzyme concentration was $0.01-0.17 \mathrm{mg} / \mathrm{ml}$.

Analysis of transfructosylation products by high-performance anion-exchange chromatography (HPAEC). Sucrose transfructosylation products were produced in $50 \mathrm{mM}$ sodium acetate ( $\mathrm{pH}$ 5.0) containing $500 \mathrm{mM}$ sucrose and 30 units of enzyme at $15^{\circ} \mathrm{C}$. After $12 \mathrm{~h}$, the reaction was stopped by heating in a boiling-water bath for $5 \mathrm{~min}$ and the products were precipitated with 3 vol. of ethanol $(100 \%(v / v))$. After centrifugation $\left(14000 \times \mathrm{g}\right.$ for $5 \mathrm{~min}$ at $\left.4^{\circ} \mathrm{C}\right)$ the supernatant was discarded and the precipitate dried by freeze-drying.

The oligosaccharides were analyzed by HPAEC (Dionex). The standards contained pentasaccharide, tetrasaccharide, trisaccharide, disaccharide sucrose, and monosaccharides glucose and fructose (Meiji Seika Kaisha Ltd). Separation of oligosaccharides was achieved by using a CarboPac PA-20 anion-exchange column $(180 \mathrm{~mm} \times 4 \mathrm{~mm}$; Dionex $)$ coupled to a CarboPac1 Guard column (Dionex). Eluent A was $0.1 \mathrm{M}$ sodium hydroxide, and eluent $\mathrm{B}$ was $0.1 \mathrm{M}$ sodium hydroxide in $0.25 \mathrm{M}$ sodium acetate. Detection was performed with an ED50 electrochemical detector (Dionex), with an Au working electrode, and an $\mathrm{Ag} / \mathrm{AgCl}$ reference electrode.

Modeling the 3D structure of $\mathrm{Z}$. mobilis levansucrase and the variants. According to the alignment and prediction using the SWISSPDB VIEWER (http://www.expasy.org/spdbv/) (Guex \& Peitsch, 1997), simulated 3D structures of the sucrose binding site were generated for Z. mobilis levansucrase and the mutant enzymes.

\section{RESULTS}

\section{Catalytic properties of recombinant levansucrases}

The sucrose hydrolysis and transfructosylation activities of all the variants were examined (Fig. 1). As compared to the wild type levansucrase, the amino acid substitutions resulted in attenuation of both the transfructosylating and hydrolyzing activities. H296R and H296W retained partial hydrolysis and transfructosylation activities; H296K, H296L and H296Q had minimal hydrolysis and transfructosylation activities; and H296C, H296S, H296E and H296Y virtually lost the activities.

H296C, H296S, H296E and H296Y had no detectable activities, so only the kinetic pa- 

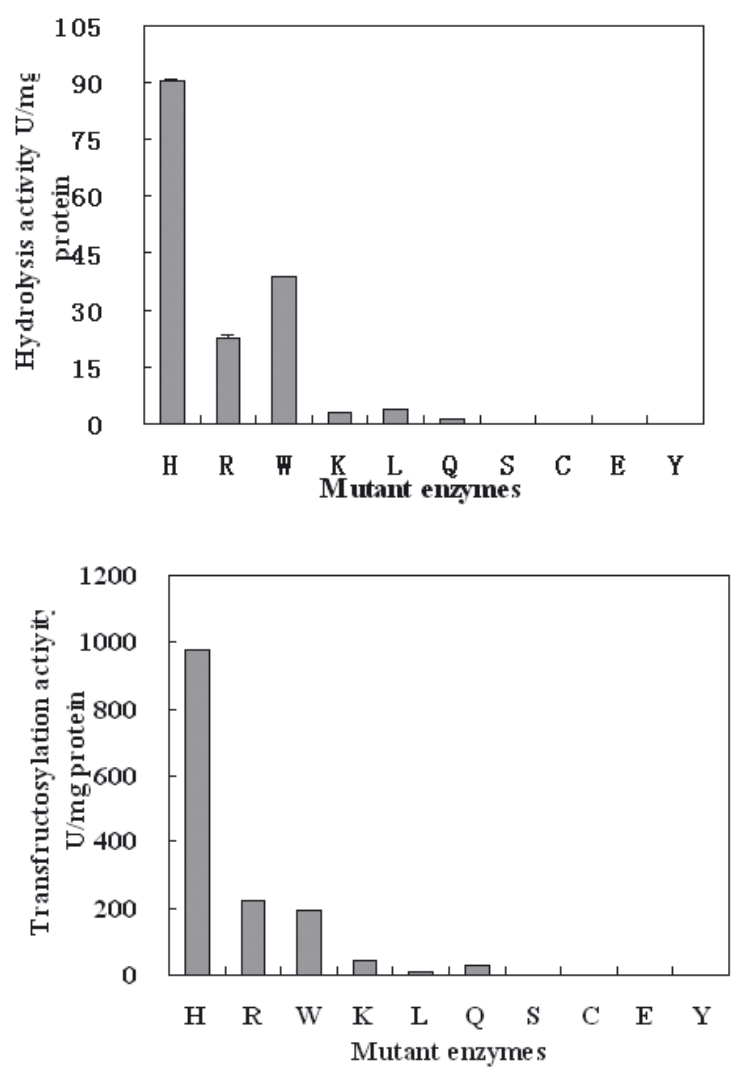

Figure 1. Analysis of hydrolysis and transfructosylation activities.

The enzyme activities were determined as described in Materials and Methods. All the experiments were repeated at least three times. H, R, W, K, L, Q, S, C, E and Y indicate the enzyme activities of SacB and the variant H296R, H296W, H296K, H296L, H296Q, H296S, H296C, H296E and H296Y, respectively.

rameters of sucrose hydrolysis for H296R, H296W, H296K, H296L and H296Q were determined (Table 2). The $k_{\text {cat }}$ value of H296R for sucrose hydrolysis was similar to that of the wild type enzyme, but its transfructosylation activity was reduced to $23.1 \%$. The H296W and H296Q mutants retained $60.6 \%$ and $66.9 \%$ ( $k_{\text {cat }}$ values) of the wild type hydrolyzing activity, respectively, whereas their transfructosylation activities were reduced to $19.8 \%$ and $2.5 \%$ of the wild type. The H296K and H296L variants displayed only residual transfructosylation activities $(4.6 \%$ and $1.0 \%$ of the wild type), but surprisingly their $k_{\text {cat }}$ values for sucrose hydrolysis were 2.5- and 1.3-fold better than the wild type. All the $K_{\mathrm{M}}$ values of the mutant enzymes were higher than the wild type value, suggesting that the affinities for sucrose were reduced.

\section{HPAEC analysis of oligosaccharides synthesized}

When the transfructosylation products derived from sucrose were analyzed using HPAEC (Fig. 2), it was found that these enzymes differed in

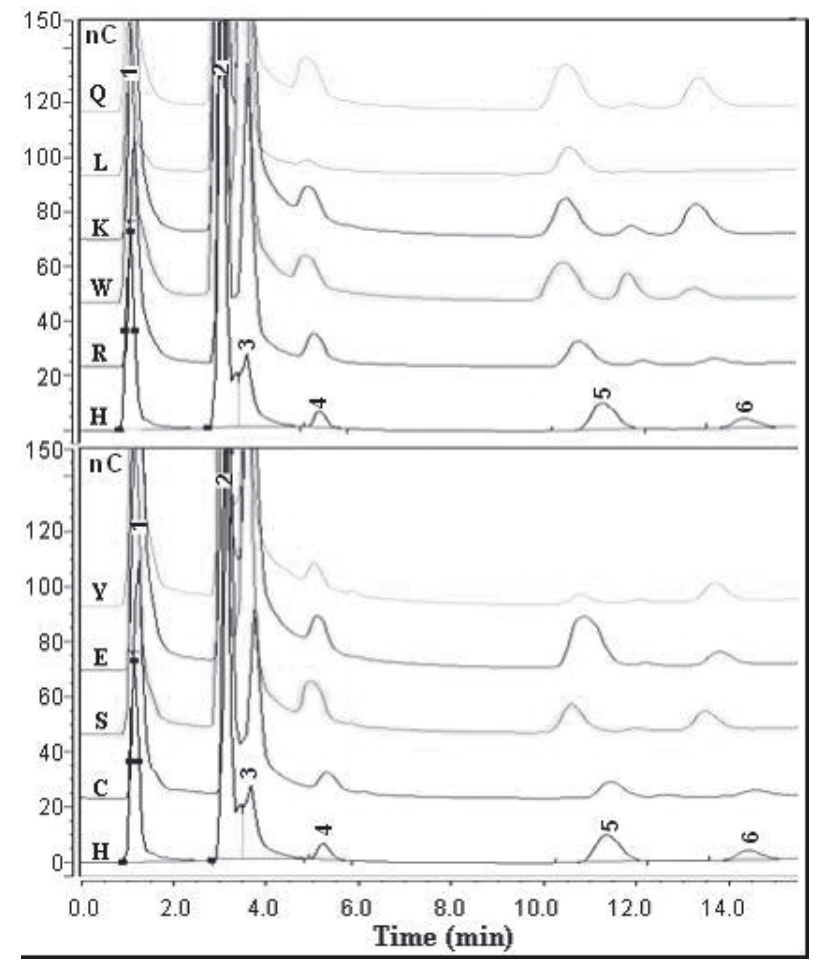

Figure 2. HPAEC analysis of oligosaccharides produced. The transfructosylation products were synthesized from $500 \mathrm{mM}$ sucrose at $15^{\circ} \mathrm{C}$ after $12 \mathrm{~h}$ incubation (using enzymes at $30 \mathrm{U} / \mathrm{ml}$ ). H, R, W, K, L, Q, C, S, E and Y indicate the oligosaccharides produced by $\mathrm{SacB}$ and the mutant enzyme H296R, H296W, H296K, H296L, H296Q, H296C, H296S, H296E and H296Y, respectively. Numbers from 1 to 6 represent the monosaccharides glucose and fructose, disaccharide sucrose, trisaccharide, tetrasaccharide, and pentasaccharide.

their product specificities. All the enzymes displayed sucrose-hydrolysis activities (producing glucose and fructose). H296L mediated the accumulation of low amounts of trisaccharide, but did not produce pentasaccharide. H296Y synthesized residual tetrasaccharide. H296W, H296K, H296Q and H296E synthesized relative more tetrasaccharide. H296R, H296W, H296K, H296Q and H296Y synthesized an additional product that could not be identified with the oligosaccharide standards.

\section{The 3D structure of $\mathrm{Z}$. mobilis levansucrase}

Based on the 3D structures of B. subtilis $\mathrm{SacB}$ and G. diazotrophicus LsdA, the structures of Z. mobilis levansucrase (Fig. 3) and their variants (not shown) were predicted. Superposition of these 3D structures revealed that the active sites of these enzymes displayed extensive overlap with each other (not shown). In the predicted structures the Z. mobilis levansucrase His296 and the substituted residues at position 296 were situated with their side chains 


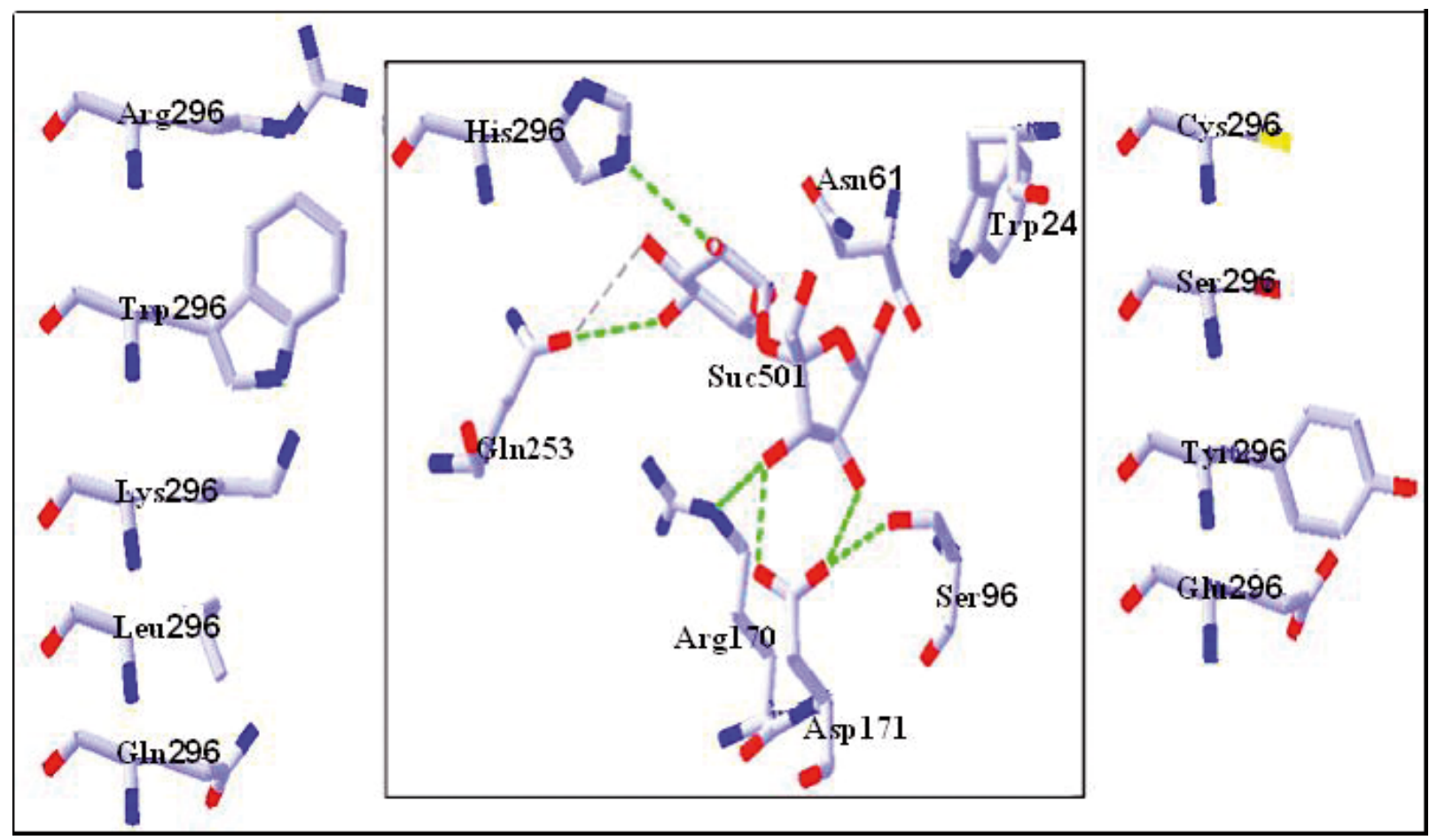

Figure 3. Molecular view of sucrose-binding pocket of Z. mobilis SacB with a bound sucrose molecule and the amino acids replacing His296.

The modeled structure of Z. mobilis levansucrase is in the box. To both sides of the box are the structures of the substituting amino acids. Hydrogen bonds are shown as dashed green lines. Suc501 marks the bound sucrose molecule.

oriented toward the entrance of the cavity. Mutation of this site did not alter the protein structure, just changed the side chain of site 296 and influenced the sucrose binding.

\section{DISCUSSION}

In Z. mobilis levansucrase, His296 corresponds to Arg331 of B. subtilis levansucrase. It was reported previously that both these site mutations influenced the transfructosylation but not the hydrolyzing activity, and the steric requirements of the active groups are more stringent for polymerization than for hydrolysis (Chambert \& Petit-Glatron, 1991; Yanase et al., 2002). In this study, the substitution of His296 with Arg, Trp or Tyr influenced both the hydrolysis and transfructosylation activities. The H296R and H296W variants retained partial hydrolysis and transfructosylation activities, but H296Y had virtually lost the catalytic activities. The Arg guanidine group and the Trp indole ring can form an electronic delocalizing plane, but the Tyr aromatic ring can not, strongly suggesting that the steric structure (electronic delocalizing plane) is important for the catalytic activities.

The positively charged Lys substitution presented the highest $k_{\text {cat }}$ (2.5-fold of the wild-type) for sucrose hydrolysis, as also reported by Chambert and Petit-Glatron (1991). Simultaneously, the short side chain (Cys or Ser) or negative (Glu) amino acid substitution virtually abolished the activities.

The high-resolution crystal structures of B. subtilis SacB and G. diazotrophicus LsdA show that the side chain of Arg331 or His419 is located immediately adjacent to the central pocket, interacting with the glucosyl residue in the active site (Meng \& Futterer, 2003; Martinez-Fleites et al., 2005). In this study, the 3D structure analysis of $Z$. mobilis levansucrase showed that His296 situated with its side chain orienting toward the entrance of the cavity and the substitutions did not obviously change the central pocket of the protein structure. The different substitutions may influence the sucrose binding, further influence sucrose hydrolysis and transfructosylation activities. The positive imidazolium group could form an electronic delocalizing plane (Chambert \& Petit-Glatron, 1991; Martinez-Fleites et al., 2005), and this steric structure made it bind the sucrose stringently. It is likely that substitutions of other amino acids formed unspecific substrate binding or did not bind the substrate because of the nonsteric or short side chains.

Our data suggest that His296 does not participate in sucrose hydrolysis or transfructosylation reaction while it acts as a site for substrate or acceptor recognizing and binding. The side chain steric structure and positive charge (forming hydrogen 
bond) of this site make levansucrase bind substrate or acceptor stringently. Firstly, His296 of Z. mobilis $\mathrm{SacB}$ recognizes and joins in the enzyme binding sucrose, subsequently the catalytic triad (Meng \& Futterer, 2003) cleaves the sucrose fructoside bond. After hydrolysis of sucrose, the resultant glucosyl moiety would be released from the enzyme-substrate intermediate; the terminal fructosyl of the acceptor would occupy the vacated glucosyl site. Then the fructosyl (binding with SacB) moiety would be transferred to the $\mathrm{C} 6$ or $\mathrm{C} 2$ site of the fructosyl moiety of the acceptor molecule. Through repetition of the hydrolysis and transfructosylation reactions, a highly polymerized fructan (levan) could be produced. The His296 mutation influenced the substrate recognizing and binding, and then had an effect on sucrose hydrolysis and fructosyl-enzyme intermediate formation. Finally, its mutations weakened the transfructosylation reaction and changed product specificities.

\section{Acknowledgements}

This work was funded by China National "863" High-Tech Program (grants no. 2005AA226030 and 2006AA02Z229) of the Ministry of Science and Technology of China.

\section{REFERENCES}

Ananthalakshmy VK, Gunasekaran P (1999) Overproduction of levan in Zymomonas mobilis by using cloned sacB gene. Enzyme Microb Technol 25: 109-115.

Bradford MM (1976) A rapid and sensitive method for the quantitation of microgram quantities of protein utilizing the principle of protein-dye binding. Anal Biochem 72: 248-254.

Chambert R, Petit-Glatron MF (1991) Polymerase and hydrolase activities of Bacillus subtilis levansucrase can be separately modulated by site-directed mutagenesis. Biochem J 279: 35-41.

Guex N, Peitsch MC (1997) SWISS-MODEL and the SwissPdb Viewer: an environment for comparative protein modeling. Electrophoresis 18: 2714-2723.

Henrissat B (1991) A classification of glycosyl hydrolases based on amino acid sequence similarities. Biochem J 280: 309-316.

Kazap I, Leibovici J, Wolman M (1980) Blood levels of high-molecular levan in mice as a function of the route and duration of administration. Arzneimittelforschung 30: 459-462.

Martinez-Fleites C, Ortiz-Lombardia M, Pons T, Tarbouriech N, Taylor EJ, Arrieta JG, Hernandez L, Davies GJ (2005) Crystal structure of levansucrase from the Gram-negative bacterium Gluconacetobacter diazotrophicus. Biochem J 390: 19-27.

Meng G, Futterer K (2003) Structural framework of fructosyl transfer in Bacillus subtilis levansucrase. Nat Struct Biol 10: 935-941.

Sarkar G, Sommer SS (1990) The "megaprimer" method of site-directed mutagenesis. Biotechniques 8: 404-407.

Senthilkumar V, Busby SJ, Gunasekaran P, Senthikumar V, Bushby SJ (2003) Serine substitution for cysteine residues in levansucrase selectively abolishes levan forming activity. Biotechnol Lett 25: 1653-1656.

Somogyi M (1952) Notes on sugar determination. J Biol Chem 195: 19-23.

Swings J, De Ley J (1977) The biology of Zymomonas. Bacteriol Rev 41: 1-46.

Yamamoto Y, Takahashi Y, Kawano M, Iizuka M, Matsumoto T, Saeki S, Yamaguchi H (1999) In vitro digestibility and fermentability of levan and its hypocholesterolemic effects in rats. J Nutr Biochem 10: 13-18.

Yanase H, Iwata M, Nakahigashi R, Kita K, Kato N, Tonomura K (1992) Purification, crystallization and properties of the extracellular levansucrase from $\mathrm{Zy}$ momonas mobilis. Biosci Biotechnol Biochem 56: 13351337.

Yanase H, Maeda M, Hagiwara E, Yagi H, Taniguchi K, Okamoto K (2002) Identification of functionally important amino acid residues in Zymomonas mobilis levansucrase. J Biochem (Tokyo) 132: 565-572.

Yun JW (1996) Fructooligosaccharides - occurrence, preparation and application. Enzyme Microb Technol 19: 107-117. 